\title{
Editorial \\ Editorial: Advanced Research in Halogen Bonding
}

\author{
Sergiy V. Rosokha ${ }^{1, *}$ and Atash V. Gurbanov $2,3, *$ (D) \\ 1 Department of Chemistry, Ball State University, Muncie, IN 47306, USA \\ 2 Centro de Química Estrutural, Institute of Molecular Sciences, Instituto Superior Técnico, Universidade de \\ Lisboa, Av. Rovisco Pais, 1049-001 Lisboa, Portugal \\ 3 Department of Chemistry, Baku State University, Z. Khalilov Str. 23, Baku AZ 1148, Azerbaijan \\ * Correspondence: svrosokha@bsu.edu (S.V.R.); atash.gurbanov@tecnico.ulisboa.pt (A.V.G.)
}

\section{check for}

updates

Citation: Rosokha, S.V.; Gurbanov,

A.V. Editorial: Advanced Research in Halogen Bonding. Crystals 2022, 12, 133. https://doi.org/10.3390/ cryst12020133

Received: 17 January 2022

Accepted: 17 January 2022

Published: 19 January 2022

Publisher's Note: MDPI stays neutral with regard to jurisdictional claims in published maps and institutional affiliations.

Copyright: (C) 2022 by the authors. Licensee MDPI, Basel, Switzerland. This article is an open access article distributed under the terms and conditions of the Creative Commons Attribution (CC BY) license (https:// creativecommons.org/licenses/by/ $4.0 /)$.
The Special Issue on "Advanced Research in Halogen Bonding" is a collection of 17 original articles reporting the results of theoretical and experimental studies that provide new insights into this fascinating intermolecular interaction.

Halogen bonding, an attraction between electrophilic halogens and nucleophilic centers, has gained increasing attention from the chemical community during the past two decades. A number of studies demonstrated that the directionality of halogen bonding and the possibility of fine tuning of its strength allow this interaction to be utilized in the preparation of functional materials by supramolecular self-assembly, molecular recognition, catalysis, drug design, etc. This collection was inspired by the recent development in this area, in particular, in applications of halogen bonding for crystal engineering in both organic and coordination compounds. It comprises two reviews and fifteen research articles from research groups from 14 different countries worldwide.

Most commonly, studies on halogen bonding focus on the interaction of halogenated electrophiles with organic nucleophiles. This trend is reflected in the current collection, in which eleven articles deal with the halogen-bonded supramolecular assemblies of organic compounds. Four papers, however, discuss halogen bonding involving coordination compounds, which is indicative of the growing interest of chemists with regard to metalion-based and hybrid materials.

A review by A. Frontera and A. Bauzá [1] provides a discussion concerning halogen bonding in the general context of $\sigma$-hole interactions in crystal structures comprising elements from groups $14-18$ and periods $3-6$. It inspects variations of $\sigma$-hole bonding when moving along the same group or the same row of the periodic table and illustrates the trends with examples from the Cambridge Structural Database (CSD) [2]. A review by E.R.T. Tiekink examines crystal architectures of the supramolecular assemblies comprising secondary I $\cdots$ Br bonding in 41 crystal structures found in the CSD [2].

A major portion of the articles in the current collection explore halogen bonding in supramolecular assemblies of organic compounds. In particular, F.I. Zubkov, A. Frontera, and co-workers [3] report results of the experimental and computational analysis of the importance of halogen bonding in two supramolecular assemblies containing four of the most abundant $(\mathrm{F}, \mathrm{Cl}, \mathrm{Br}$, and I) halogen atoms. L. Fotović and V. Stilinović [4] explore the effects of alkyl substituents on halogen bonding in $\mathrm{N}$-alkyl-3-halogenopyridinium salts. These authors show that N-ethylated ions form stronger halogen bonds (due to more positive $\sigma$-hole bonds) than their methylated analogues. The role of halogen substituents on halogen bonding in 4,5-dibromohexahydro-3a,6-rpoxyisoindol-1 $(4 \mathrm{H})$-ones is discussed by A.V. Gurbanov, H.H. Truong et al. [5]. The influence of halogen substituents on the self-assembly and crystal packing of multicomponent crystals of ethacridine and metahalobenzoic acids is examined in a paper by A. Mirocki and A. Sikorski [6].

Y. Takemoto, Y. Kobayashi and co-authors report the successful synthesis of ortho${ }^{t} \mathrm{BuSO}_{2} \mathrm{C}_{6} \mathrm{H}_{4}$-substituted iodonium ylides (which are known for their variety of synthetic 
applications) [7]. This research group estimate the strength of the intra- and intermolecular halogen-bonding interactions in the ylides salts and investigate their photoreactions. V. Stilinović, D. Cinčić and co-workers evaluate the tautomeric equilibrium of an asymmetric $\beta$-diketone in halogen-bonded cocrystals with perfluorinated iodobenzenes [8]. The behavior of the amine group as a halogen-bond acceptor in cocrystals formed by aromatic diamines and perfluorinated iodobenzenes is reported by V. Stilinović, D. Cinčić et al. [9] In agreement with the calculated halogen and hydrogen bond energies, these crystals show a preferable formation of the halogen $\mathrm{N}$... I bonds as opposed to hydrogen bonds (with amine as a donor). The competition and cooperation of halogen and hydrogen bonds is also explored in the halogen-bonding-driven self-assembly of tetrabromoterephthalic solvates by K. Chainok et al. [10] In comparison, C.E. Housecroft and co-workers report a changeover from the predominance of $\mathrm{C}-\mathrm{Br} \cdots \pi$ (arene) to $\mathrm{C}-\mathrm{H} \cdots \mathrm{Br}$ and $\mathrm{Br} \cdots \mathrm{Br}$ noncovalent interactions in the crystal of 1,4-dibromo-2,5-bis(phenylalkoxy)benzene derivatives [11].

M.M. Popa, F. Dumitrascu et al. explore 5-Iodo-1-arylpyrazoles as potential benchmarks for investigating the tuning of halogen bonding [12]. An ultimate example of such tuning is reported by S.V. Rosokha et al. [13]. These authors show that by varying the brominated electrophile, halogen $\mathrm{Br} \cdots \mathrm{Cl}$ bond strength and length can be altered gradually from the values common in weak intermolecular complexes to those values approaching a fully developed covalent bond.

Another group of papers deals with the halogen bonding in coordination compounds. In particular, E. Constable and C. Housecroft explore structural motifs in the tris $\left(2,2^{\prime}-\right.$ bipyridine) metal complexes with halide counterions in the CSD [14]. D. Ivanov, M. Kinzhalov et al. analyze the role of halogen bonding and other noncovalent interactions in the crystal packing of $\mathrm{Pd}(\mathrm{II})$ and $\mathrm{Pt}(\mathrm{II})$ isocyanide complexes [15]. The results of the X-ray structural analysis of these complexes are rationalized using DFT computations and topological analysis. A similar combination of experimental and computational methods is utilized by $\mathrm{Q}$. Wu and co-workers for the analysis of the structural features and halogen bonding in a Mn(III) complex bearing halogenated Schiff-base ligands [16]. Finally, halogen bonding involving $\mathrm{I}_{2}$ and $\mathrm{d}^{8}$ transition-metal pincer complexes is systematically investigated in a computational study by E. Kraka et al. [17] These authors reveal the major electronic effects in the catalytic activity of the M-I-I non-classical three-center bond of the pincer complex, which is involved in the oxidative addition of $\mathrm{I}_{2}$ molecule to the metal center.

As can be seen from the contents of collection, the preparation and characterization of novel halogen-bonded assemblies, computational studies of this interaction and analyses of the X-ray structural data available in the CSD provide new, interesting data about this intermolecular interaction. These works advance the concept of the halogen bond as an effective building synthon in supramolecular chemistry of organic and coordination compounds. We hope that this collection will stimulate the exchange of ideas, encourage the development of new synthetic concepts and theoretical investigations of various classes of organic and coordination compounds, as well as motivate PhD students and newcomers to start exciting research in the field of crystal engineering.

Author Contributions: Conceptualization, data curation, writing-original draft preparation, review and editing, S.V.R. and A.V.G. All authors have read and agreed to the published version of the manuscript.

Funding: S.V.R. is thankful to the National Science Foundation for the financial support of his past and present research projects related to halogen bonding (Grants CHE-2003603, CHE-1607746 and CHE-1112126), which, to some extent, have enabled him to be a Guest Editor of this Special Issue. This work has been partially supported by the Fundação para a Ciência e a Tecnologia (FCT), Portugal, through projects UIDB/00100/2020 and UIDP/00100/2020 of Centro de Química Estrutural and IMS-LA/P/0056/2020. A.V.G. thanks the FCT and Instituto Superior Técnico (DL 57/2016 and L 57/2017 Program, Contract no: IST-ID/110/2018). 
Acknowledgments: A contribution of all authors is gratefully acknowledged. We would like to express our gratitude to the editorial staff of Crystals.

Conflicts of Interest: The authors declare no conflict of interest.

\section{References}

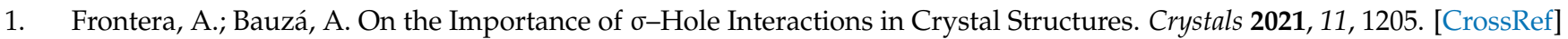

2. Tiekink, E. Characterising Supramolecular Architectures in Crystals Featuring I ․ Br Halogen Bonding: Persistence of X . . X' Secondary-Bonding in Their Congeners. Crystals 2021, 11, 433. [CrossRef]

3. Mertsalov, D.F.; Gomila, R.M.; Zaytsev, V.P.; Grigoriev, M.S.; Nikitina, E.V.; Zubkov, F.I.; Frontera, A. On the Importance of Halogen Bonding Interactions in Two X-ray Structures Containing All Four (F, Cl, Br, I) Halogen Atoms. Crystals 2021, 11, 1406. [CrossRef]

4. Fotović, L.; Stilinović, V. Halogen Bonding in N-Alkyl-3-halogenopyridinium Salts. Crystals 2021, 11, 1240. [CrossRef]

5. Gurbanov, A.; Mertsalov, D.; Zubkov, F.; Nadirova, M.; Nikitina, E.; Truong, H.; Grigoriev, M.; Zaytsev, V.; Mahmudov, K.; Pombeiro, A. Role of Halogen Substituents on Halogen Bonding in 4,5-Dibromohexahydro-3a,6-epoxyisoindol-1(4H)-ones. Crystals 2021, 11, 112. [CrossRef]

6. Mirocki, A.; Sikorski, A. Influence of Halogen Substituent on the Self-Assembly and Crystal Packing of Multicomponent Crystals Formed from Ethacridine and meta-Halobenzoic Acids. Crystals 2020, 10, 79. [CrossRef]

7. Kimura, T.; Hamada, S.; Furuta, T.; Takemoto, Y.; Kobayashi, Y. Synthesis and Properties of ortho-t-BuSO $\mathrm{B}_{2} \mathrm{C}_{6} \mathrm{H}_{4}-\mathrm{Substituted}$ Iodonium Ylides. Crystals 2021, 11, 1085. [CrossRef]

8. Martinez, V.; Bedeković, N.; Stilinović, V.; Cinčić, D. Tautomeric Equilibrium of an Asymmetric $\beta$-Diketone in Halogen-Bonded Cocrystals with Perfluorinated Iodobenzenes. Crystals 2021, 11, 699. [CrossRef]

9. Uran, E.; Fotović, L.; Bedeković, N.; Stilinović, V.; Cinčić, D. The Amine Group as Halogen Bond Acceptor in Cocrystals of Aromatic Diamines and Perfluorinated Iodobenzenes. Crystals 2021, 11, 529. [CrossRef]

10. Chongboriboon, N.; Samakun, K.; Dungkaew, W.; Kielar, F.; Sukwattanasinitt, M.; Chainok, K. Halogen-Bonding-Driven Self-Assembly of Solvates of Tetrabromoterephthalic Acid. Crystals 2021, 11, 198. [CrossRef]

11. Manfroni, G.; Prescimone, A.; Constable, E.; Housecroft, C. 1,4-Dibromo-2,5-bis(phenylalkoxy)benzene Derivatives: C-Br. $\pi$ (arene) Versus C-H. Br and Br. Br Interactions in the Solid State. Crystals 2021, 11, 325. [CrossRef]

12. Dumitrescu, D.; Shova, S.; Man, I.C.; Caira, M.R.; Popa, M.M.; Dumitrascu, F. 5-Iodo-1-arylpyrazoles as Potential Benchmarks for Investigating the Tuning of the Halogen Bonding. Crystals 2020, 10, 1149. [CrossRef]

13. Loy, C.; Zeller, M.; Rosokha, S.V. Halogen Bonding in the Complexes of Brominated Electrophiles with Chloride Anions: From a Weak Supramolecular Interaction to a Covalent Br-Cl Bond. Crystals 2020, 10, 1075. [CrossRef]

14. Constable, E.; Housecroft, C. Halide Ion Embraces in Tris(2,2'-bipyridine)metal Complexes. Crystals 2020, 10, 671. [CrossRef]

15. Kashina, M.; Ivanov, D.; Kinzhalov, M. The Isocyanide Complexes cis- $\left[\mathrm{MCl}_{2}\left(\mathrm{CNC}_{6} \mathrm{H}_{4}-4-\mathrm{X}\right)_{2}\right](\mathrm{M}=\mathrm{Pd}, \mathrm{Pt} ; \mathrm{X}=\mathrm{Cl}, \mathrm{Br})$ as Tectons in Crystal Engineering Involving Halogen Bonds. Crystals 2021, 11, 799. [CrossRef]

16. Wu, Q.; Xiao, J.-C.; Zhou, C.; Sun, J.-R.; Huang, M.-F.; Xu, X.; Li, T.; Tian, H. Crystal Structure and Supramolecular Architecture of Inorganic Ligand-Coordinated Salen-Type Schiff Base Complex: Insights into Halogen Bond from Theoretical Analysis and 3D Energy Framework Calculations. Crystals 2020, 10, 334. [CrossRef]

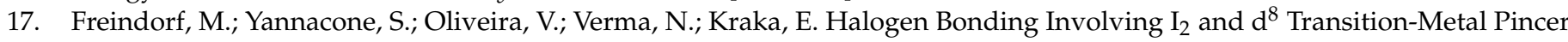
Complexes. Crystals 2021, 11, 373. [CrossRef] 